\title{
EL 98 DESDE UNA PERSPECTIVA NORMALIZADORA. REFLEXIÓN HISTORIOGRÁFICA DE UN CENTENARIO**
}

\author{
por \\ M. ${ }^{a}$ Dolores Elizalde PÉReZ-Grueso \\ Instituto de Historia, CSIC
}

\section{EL REPLANTEAMIENTO DEL 98 DESDE UNA PERSPECTIVA NORMALIZADORA}

Probablemente todavía sea pronto para hacer un balance realista de lo que ha supuesto el replanteamiento de la crisis de 1898, cien años después de que ésta ocurriera. Las variaciones en las interpretaciones históricas tardan en asimilarse, y sólo al cabo de los años nos damos cuenta de que realmente en algún momento dado, a través de una o de varias obras, mediante determinados debates, se aportaron una serie de conocimientos o de perspectivas nuevas que hicieron que se fuera transformando nuestra valoración de los hechos. Pasada la conmemoración se han oído voces críticas resaltando que con ocasión del centenario del 98 se ha hecho poco, que apenas nada nuevo se ha aportado, que no ha habido ninguna publicación revolucionaria al respecto. También se ha cuestionado el exceso de complacencia con la que se han revisado los acontecimientos, los esfuerzos por volver a analizar aquellos momentos desde una perspectiva positiva que arrojara luz sobre aquella coyuntura como hito en la modernización de España, y le quitara buena parte del dramatismo autoflagelador. Es cierto que no ha habido descubrimientos espectaculares respecto a lo ocurrido en 1898. Sin embargo, después de la reflexión colectiva que se ha producido con ocasión del

\footnotetext{
* Este artículo se realiza dentro del proyecto PB96-0914.
} 
centenario, se ha cambiado la perspectiva desde la que se contemplaba el 98. Se han publicado una serie de libros valiosos, en los que han colaborado muchos de nuestros mejores historiadores, que han rebatido imágenes recurrentes, han reajustado el funcionamiento de los mecanismos, precisando temas y matizando afirmaciones. Las pequeñas variaciones introducidas a través de esas obras deberían conseguir que cambiara la imagen final del conjunto.

Actualmente, el 98 ya no se contempla sólo como «el Desastre». Incluso se cuestiona la existencia de una crisis referida a esa fecha como coyuntura concreta, como resultado de una guerra puntual, como efecto de la pérdida de las colonias, como consecuencia de lo ocurrido en ese único año. En las últimas reflexiones al respecto se han enriquecido y ampliado los contenidos del 98 y se ha pasado a hablar de fin de siglo como referencia más exacta y completa. Cien años después de los hechos, los autores contemporáneos que se han detenido a repensar el 98 han puesto el énfasis en desdramatizar aquel momento histórico. En superar la imagen del «Desastre» como fenómeno privativo de España, como síntoma de los «males de la patria», consecuencia de «la degeneración de la raza». Se han esforzado en cuestionar el «España como problema» - aunque no el «Europa como solución»-, en negar la exclusividad de los conflictos, en rebatir la excepcionalidad de la historia española.

Alcanzada en España la normalidad democrática e incorporado el país al conjunto de las naciones que nos rodean en los más variados aspectos —con sus luces y sus sombras-, podemos replantear los problemas sin complejos que nos lleven a subrayar las diferencias ni a explicarlos a través de la peculiar singularidad del ser español. Desde esa nueva posición es más fácil una labor que en cualquier ocasión debería ser indispensable: situar los problemas en el contexto internacional que les corresponde. Esa perspectiva, junto con los avances en el conocimiento sobre determinados campos — como el económico, el político, el institucional, el social o el internacional-, nos ha permitido establecer paralelismos entre el fin de siglo español y los últimos años del XIX en otros países de nuestro entorno. Se comparan sistemas políticos e instituciones, desarrollos económicos, intercambios comerciales y líneas de crecimiento, se confrontan problemas sociales, estallidos de violencia, malestares sociales, políticas internacionales y actuaciones coloniales. Se sitúan, además, cada uno de esos aspectos, en un marco internacional común. Y se comprende que España, con sus características propias y sus conflictos específicos, no fue una nación excepcionalmente castigada en 1898 por una crisis surgida de unos problemas nacionales, únicos e insuperables. Evidentemente hubo conflictos y carencias en muy diversos ámbitos, pero fueron problemas equiparables a los de otros países del entorno. Sin obviar los conflictos y las rémoras, en los trabajos recientes sobre 1898 se ha prestado un especial interés en destacar el proceso de modernización que vivía España en el fin de siglo, en el que indudablemente incidió el 98, pero sin sumir por ello al país en una crisis originada en esa coyuntura. Por contra, diversos autores han subrayado que la crisis apenas se dejó notar en campos tan

Hispania, LXI/2, núm. 208 (2001) 707-736 
fundamentales como la economía o el comercio. Y que, en todos los casos, el 98 supuso un autentico revulsivo para mejorar España, para «regenerarla».

Si hubiera que destacar una serie de puntos en los que ha incidido este replanteamiento del 98 podrían ser: la normalización de la historia española; la revalorización de la Restauración como régimen político parlamentario estable con alternancia de partidos en el poder, aún señalando las graves limitaciones que a la larga le llevarían a su propio agotamiento; la contextualización de la coyuntura 1898 en un entorno internacional similar; la insistencia en el proceso de modernización que entonces vivía España, a pesar de que en muchos campos partía de unas posiciones retrasadas respecto a la media europea; y la afirmación del espíritu regeneracionista que impulsó 1898. Veamos, pues, el 98 como un punto de inflexión en la modernización de España que - años después- en algún momento se frustró, con unas dramáticas consecuencias que ha costado muchas décadas superar hasta conseguir instalar a España en la normalidad democrática y en el mismo horizonte de desarrollo económico, social e institucional que los países que nos rodean.

Desde esa perspectiva, quizás la conclusión más obvia de la revisión del 98, cien años después, haya sido la desdramatización de la derrota. En el enfrentamiento con los Estados Unidos se perdió la guerra y con ella las posesiones coloniales en el Caribe y en el Pacífico. Pero ello no ocurrió porque España fuera un ente especialmente decadente ni pervertido, ni porque se hubiera producido una degeneración de la raza, o porque se hubiera desvirtuado la esencia del ser español. Fue una mera derrota ante una nación militar y económicamente superior que iniciaba entonces su expansión colonial; esta expansión se produjo precisamente a costa de unos territorios que España fue incapaz de defender por falta de medios, por la ausencia de apoyos mayoritarios a la administración española por parte de las poblaciones autóctonas, las cuales por razones obvias no defendieron el mantenimiento de ese sometimiento, y por la carencia de apoyos internacionales frente a un rival que por aquél entonces, dijera lo que dijera la prensa española de la época, era una potencia - y un socio comercial mucho más poderoso que España, y a la que ningún país quiso enfrentarse. Esa derrota, perfectamente explicable en el contexto adecuado, no produjo además una crisis política, institucional, social o económica que justificara hablar de desastre nacional. Sólo la crisis en la consciencia de los contemporáneos y su amarga reflexión sobre España condujeron a la magnificación de unos hechos que hoy en día se contemplan de manera más templada.

\section{PRINCIPAles CUESTIONES TRATADAS EN ESTE REPENSAR EL 98 CIEN AÑOS DESPUÉS}

Desde esa perspectiva normalizadora de la historia española, ha habido una serie de cuestiones que han catalizado el interés de los historiadores. No ha sido

Hispania, LXI/2, núm. 208 (2001) 707-736 
el 98 en sí la única coyuntura histórica que se ha replanteado, sino que esa revisión ha estado ligada a las que paralelamente se han realizado sobre la Restauración como modelo político, y sobre Antonio Cánovas del Castillo como hombre de Estado. Otros temas relativos a nuestra historia de hace cien años, otras figuras políticas, podrían haberse estudiado con tanta o más razón, pero por los motivos que fuera - especial interés político, énfasis institucional en determinados aspectos - han sido esas tres cuestiones - la Restauración, Cánovas y el 98- las que han centrado la atención de los académicos y las que han monopolizado congresos, seminarios, exposiciones y conferencias. De ahí la abundante publicística aparecida en torno a estos asuntos íntimamente ligados. Entre los principales temas que se han tratado merecen destacarse una serie de cuestiones.

1- Una reflexión sobre el sistema político de la Restauración, unida a la revisión de la figura de Cánovas como estadista y a la construcción de un Estado liberal. Se han subrayado los méritos de aquél período en tanto que afirmó en España el sistema parlamentario democrático - con las limitaciones propias de la época-, propició el turno pacífico de los partidos en el ejercicio del poder, acabó con el intervencionismo militar, y ofreció al país la estabilidad necesaria para superar las convulsiones políticas que habían caracterizado al siglo XIX. Se han criticado, por contra, las limitaciones a la apertura, la incapacidad para incorporar tendencias políticas y aspiraciones sociales ajenas a la élite gobernante, el abuso del clientelismo en la vida política, la desvirtuación de un verdadero sistema representativo. Y al tiempo, se ha analizado más allá de esas críticas - superando la condena moral—, y se ha subrayado que, pese a que el planteamiento electoral de la Restauración legitimaba una farsa en la cual unas élites determinaban quiénes y en qué número debían de estar representados en las Cortes, fue precisamente el caciquismo el mecanismo que aseguró el correcto funcionamiento del sistema y el turno casi matemático de los partidos políticos en el gobierno de la nación.

2- Un replanteamiento del tema colonial, en el cual se ha ańalizado con objetividad la política colonial española en los territorios ultramarinos del Caribe y del Pacífico, señalando los errores de aquél régimen, pero también los avances que permitió, insistiendo en la vitalidad que todavía tenía el imperio español de fines de siglo. Se ha trabajado con especial énfasis sobre los grupos coloniales y los intereses económicos que les sustentaban, tantas veces silenciados tras unas miras humanitarias y evangélicas que parecía más conveniente resaltar. Este replanteamiento se ha realizado, además, en constante diálogo entre las poblaciones de todos aquellos territorios metropolitanos o coloniales. Cubanos, españoles, puertorriqueños, filipinos y micronesios se han reunido a debatir la historia que les unía y la historia que les separaba, produciéndose un común enriquecimiento en los planteamientos.

3- Una impugnación de las teorías sobre la crisis económica que asoló España en 1898. Los historiadores económicos han revisado la evolución de la 
economía, las consecuencias de la guerra y de las deudas que acarrearon, los trasvases de capital, la continuidad del comercio con los territorios coloniales, las relaciones económicas con otros países, las mejoras conseguidas tras el 98, el saneamiento económico que produjo. A consecuencia de lo cual han reafirmado la línea en la que ya venían trabajando muchos de ellos, resaltando que, en el campo de la economía, 1898 no puede considerarse una coyuntura de crisis, ni el comienzo de una deflacción, sino todo lo contrario. Ya no se subraya el fracaso económico ni se destaca el estancamiento de la economía, sino que se defiende que en España, aunque se partía de una situación de retraso, en los últimos años del siglo XIX existió un crecimiento económico comparable al de otros países europeos. Se vivió un período de modernización de las estructuras y de expansión de los mercados, en el cual el 98 no supuso una quiebra, sino una continuidad en las tendencias alcistas. Produjo además una serie de efectos -repatriación de capitales, fin de la sangría colonial y de las guerras ultramarinas, equilibrio presupuestario, replanteamiento hacendístico- que incrementaron el crecimiento económico que ya existía.

4- En el tema de las mentalidades, se ha revisado el horizonte intelectual de los coetáneos a 1898, marcado por una crisis en la identidad nacional y en los valores patrios - les dolía España-. Pero esa crisis, inserta a su vez en la decadencia del positivismo y el auge del vitalismo, no fue ajena tampoco a los planteamientos que se hacían los intelectuales de los países de nuestro entorno. Se ha puesto en particular relación con las reflexiones francesas provocadas por la derrota de Sedán de 1870. Al tiempo, los intelectuales, que ocupaban por primera vez un importante papel social, destacaron por su clara intención regeneracionista y por una fecunda producción en numerosos campos del saber -fue entonces la edad de plata de la cultura española-. El regeneracionismo, en el cual se distinguen matices y generaciones, se vio impulsado por el 98, pero era un sentimiento que ya existía en el seno de la sociedad española desde muchos años antes del fin de siglo.

5- En las últimas décadas, más allá de la conmemoración del 98 , se ha revisado también la situación social de aquella España finisecular, incidiendo en la conflictividad, en la aparición de nuevos movimientos sociales, en la manifestación de las tensiones, duramente reprimidas por un Régimen que trataba de obviarlas y olvidarlas. Se ha quebrado con ello la imagen de estabilidad de la Restauración, subrayando los conflictos subterráneos que explican los estallidos de violencia vividos en la primera mitad del siglo XX.

6- Con ocasión del centenario, se ha recordado que en torno a 1898 hubo un despertar de los nacionalismos en distintas partes de España, los cuales plantearon unas soluciones regionales a los problemas del país, y reclamaron el reconocimiento de unos derechos y de unas instituciones propias y diferenciadas dentro del marco nacional. En una España actual en la cual los problemas nacionalistas están en plena vigencia, los primeros pasos de ese proceso necesariamente tenían que despertar interés. Esos nacionalismos peninsulares coinci- 
dieron además con la explosión nacionalista en Ultramar, donde las poblaciones de las colonias estaban inmersas en procesos de construcción nacional y de afirmación de una identidad propia; los cuales, en los últimos años del siglo, les habían llevado a rebelarse contra España y a luchar por su independencia. El tema de la identidad y de la construcción nacional en Cuba, Filipinas y Puerto Rico ha sido objeto de atención preferente por parte de los historiadores.

7- Se ha producido también una revisión de la situación del Ejército y de la Marina en el fin de siglo, destacando que no fue tanto la carencia de unos medios adecuados como la falta de eficacia de esos medios recién adquiridos, la ausencia de una estrategia definida y suficientemente planificada, y la inadecuación de los recursos a las verdaderas necesidades españolas, los factores que condujeron a la derrota militar - $y$ en este punto nadie niega el rotundo fracaso- y al profundo replanteamiento de lo que era y lo que debía ser el Ejército en el seno de la sociedad española.

8- Finalmente, se ha proseguido con el estudio del contexto internacional, incidiendo en la línea iniciada por Jesús Pabón y por José M. ${ }^{a}$ Jover, que situaba al 98 español en el mismo contexto de otras crisis coloniales similares vividas por los países de nuestro entorno, en el momento del cénit de la expansión imperialista. En los últimos años se han introducido importantes matices a aquellos planteamientos iniciales: se ha cuestionado la tesis que incidía en la ausencia de una verdadera política exterior española, señalando que la participación española en la escena internacional fue mayor de la reconocida hasta el momento; se han diferenciado y graduado las distintas crisis coloniales vividas por los países de nuestro entorno en los últimos años del XIX; se han subrayado los cambios en la situación mundial - ya no eurocéntrica-, la decisiva irrupción de Estados Unidos en ese ámbito y los efecto que ello tuvo sobre la posición española; y se ha incidido en la estrecha relación entre economía y política exterior, señalando cómo todas estas cuestiones tuvieron una directísima influencia en la actuación internacional que España desempeñó en 1898.

\section{REVISIÓN DE TRABAJOS}

En los últimos años cada universidad, cada revista, cada seminario, ha querido hacer su particular revisión del 98 , traer a sus aulas o a sus páginas ese debate, tener ocasión de discutir y repensar la crisis de 1898. Ello ha hecho se hayan celebrado multitud de congresos, reuniones y conferencias, y que como resultado de todo ello hayan aparecido muchas publicaciones colectivas y numerosas obras individuales - aunque bastantes menos que las colectivas-, cada una de ellas con sus ventajas, sus inconvenientes y sus inevitables reiteraciones. Entre todos estos actos y obras, —ante la imposibilidad de analizarlos uno por uno en su totalidad, lo cual no es en absoluto el objetivo de este traba- 
jo- vamos a destacar los que consideramos que han supuesto hitos importantes para el tema —en una apreciación obviamente personal y cuestionable-.

\section{- Reuniones y Congresos}

Una de las primeras ocasiones que reunió a los especialistas fue el Congreso celebrado en Aranjuez en Abril de 1995 bajo el sugerente título de La Nación soñada: Cuba, Puerto Rico y Filipinas ante el $98^{1}$. Lo que pretendían sus organizadores, Consuelo Naranjo, Miguel Ángel Puig-Samper y Luis Miguel García Mora, era plantear la realidad de estas tres colonias en los años anteriores a la pérdida de su vinculación a la Metrópoli. Se quería incidir en la construcción y la consolidación nacional en los ámbitos coloniales, y en las diferentes sociedades existentes en cada una de aquellas islas - Rebecca Scott, Paul Estrade, Jorge Ibarra, Luis Agrait, Alejandro de la Fuente, Astrid Cubano-; en la política colonial desarrollada por España - José Antonio Piqueras, Joan Casanovas, José Cayuela-; en la enseñanza, la ciencia, las mentalidades, y los respectivos referentes intelectuales - Teresa Muñoz, Carmen Almodovar, Aurea Matilde Fernández, Pablo Tornero-; en la evolución económica y en la divergencia de intereses entre Metrópoli y colonias - Alejandro García, Jordi Maluquer, Josep M. Delgado-; en el contexto internacional que rodeaba a las colonias en los últimos años del XIX - Carlos Serrano, Manuel Espadas, Fernando García Sanz-. Se trataron todos esos temas, y las orientaciones de los trabajos se inclinaron ya hacia el 98 mucho más allá de la intención inicial prenoventayochista. El resultado de esa reunión fue un libro magnífico, uno de los mejores aparecidos en los últimos años sobre el tema, imprescindible para el estudio de la realidad colonial española. Como todas las obras colectivas, - y en éste participaron un buen número de especialistas - peca de una excesiva dispersión que impide una coherencia global y un mismo nivel de calidad en todas las intervenciones, pese a lo cual el libro reúne una serie de artículos ineludibles para conocer la situación de España, Cuba, Puerto Rico y Filipinas en torno a 1898, además de una muy útil recopilación bibliográfica.

El mismo espíritu pre-98 animó a Juan Pablo Fusi y a Antonio Niño a convocar en la Universidad Complutense un congreso dedicado a estudiar los antecedentes del 98. Tuvo un doble reflejo: un primer volumen, Antes del Desastre: Orígenes y antecedentes de la crisis del $98^{2}$, en el que se reunieron las comunicaciones - entre ellas destacar las de Lario, Sierra, Moreno, Navajas, Cuartero, Marimón, Companys...- presentadas en torno a varias cuestiones: el Estado y

1 Naranjo, Consuelo; Puig-SAmper, Miguel Ángel y García, Luis Miguel, eds.: La nación soñada: Cuba, Puerto Rico y Filipinas ante el 98, Madrid, Doce Calles, 1996.

2 Fusi, Juan Pablo y NiÑO, Antonio, eds.: Antes del «Desastre». Orígenes y antecedentes de la crisis del 98, Madrid, Universidad Complutense, 1996. 
la sociedad durante la década de 1890; el Ejército y la Marina antes del 98; la política colonial y el despertar de los nacionalismos en Ultramar; la situación internacional y la política exterior española en los años noventa; y los intelectuales y «el problema de España». En un segundo volumen, más cohesionado, aparecieron las ponencias bajo el título de Vísperas del $98^{3}$. En él merecen destacarse como aportaciones importantes el análisis del Estado y la sociedad de los 90 realizado por José Alvarez Junco; las tesis sobre el funcionamiento de la vida política a través de los partidos y las elecciones mantenidas por Carlos Dardé; la modernización económica apuntada por Antonio Gómez Mendoza; las impresiones de la realidad colonial — sólo antillana - obtenidas en los trabajos de Elena Hernández Sandoica, Jorge Ibarra y Astrid Cubano; la esquematización de la política exterior española conseguida por Rosario de la Torre; y la reflexión de Vicente Cacho Viu sobre la crisis del positivismo. Sin desmerecer otros artículos - realizados por autores tan valiosos como José M. ${ }^{\mathrm{a}}$ Jover hablando de civilización, Manuel Espadas tratando del Ejército, José Carlos Mainer sobre Galdós, o Francisco Villacorta en relación con el pensamiento social de la Restauración-, en los trabajos mencionados se apuntan ya las principales tesis que hoy en día se manejan en la historiografía española acerca del período finisecular.

El Consejo Superior de Investigaciones Científicas convocó en Octubre de 1996 un Coloquio dirigido por Consuelo Naranjo, en el que se planteaba el quid de la cuestión: 1898, ¿ruptura o continuidad? a través de cuatro flancos: América en la coyuntura finisecular — coordinado por Dolores GonzálezRipoll y Luis Miguel García-; 1898 en España: Estado y Sociedad, Economía, Marco Internacional y Política colonial — coordinado por M. ${ }^{a}$ Dolores Elizalde-; Ciencia y regeneración en España - coordinado por Ricardo Campos y Rafael Huertas-; y Aspectos religiosos del 98 - coordinado por José Andrés Gallego-. Fue una espléndida oportunidad para el debate - recuerdo como especialmente interesantes aquellos que reunieron a Juan Pablo Fusi, José Alvarez Junco y Sebastian Balfour en torno a cuestiones políticas, y a Pablo Martín

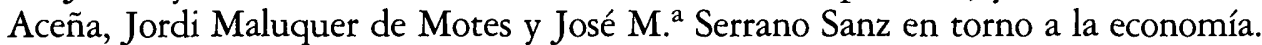
El único pero importante de aquella reunión fue la no publicación de sus actas. Las cuestiones planteadas quedaron en el aire, aunque afortunadamente los razonamientos de los autores se plasmaron luego a través de otras publicaciones.

Desde entonces, años antes del centenario oficial, se multiplicaron los congresos referentes al 98. Podemos citar la reunión organizada por Pedro Tedde de Lorca en la Universidad de Valladolid, Antecedentes y consecuencias del 98; el encuentro internacional Independencia y modernidad: Cuba y España en la coyuntura del 98, organizado por Antonio Escudero en la Universidad de Alicante; el coloquio El fin de un Imperio: balance económico, dirigido por Nicolás SánchezAlbornoz en Oviedo; varias reuniones en torno al 98 organizadas por la Casa

\footnotetext{
3 Fusi, Juan Pablo y NiÑo, Antonio, eds.: Vísperas del 98, Madrid, Biblioteca Nueva, 1997.
} 
de Velázquez; las Lecciones de un fin de siglo, organizadas por la Residencia de Estudiantes; el congreso El Imperio perdido. El 98 desde América, convocado por la Asociación Española de Historia Contemporánea en Sevilla; y como cierre, el simposio internacional De ayer a boy. Los fines de siglo en España, Cuba, Puerto Rico y Filipinas: Una perspectiva comparada, dirigido por Antonio Morales Moya y Mariano Esteban en la Universidad de Salamanca, en el cual se tendían ya puentes y se establecían paralelismos entre dos fines de siglo, el ochocentista y el novocentista. También se han celebrado cursos de verano relativos 1898: la Universidad Complutense organizó en El Escorial sendos seminarios dirigidos por Emilio de Diego y Octavio Ruiz Manjón; la Universidad de Oviedo presentó un ciclo coordinado por Moisés Llordén y por Germán Ojeda; y como éstos, otros muchos en una lista imposible de reseñar en su totalidad si queremos trascender la mera labor de testimonio factual. Por ello, entre tantos acontecimientos, vamos a detenernos sólo en tres reuniones científicas.

En primer lugar, el Congreso internacional Los 98 ibéricos y el mar ${ }^{4}$, coordinado por Antonio Morales Moya en el marco de la Expo de Lisboa 98. Este simposio tuvo un carácter diferenciador porque puso el acento en el estudio comparado de la situación española y portuguesa en 1898 en muy diversos campos, y en el reflejo de ambas sociedades en el mar. El Comisario de la Expo 98, Luis Miguel Enciso resaltaba, en el prólogo de la obra resultante, cómo una cierta historiografía había hecho de 1898 el símbolo de todos los desastres. Sin embargo, hoy en día, proseguía Enciso, tienden a verse las cosas de otra manera: sin negar el efecto traumático que tuvieron la derrota militar, la pérdida de las últimas colonias y la crisis consiguiente, no pocos historiadores, hombres de letras, ensayistas, periodistas interesados en la etapa finisecular, ponen de relieve que el 98 fue un revulsivo para reordenar la convivencia dentro de España, para articular una conciencia regeneracionista, y para adoptar un nuevo papel en la política internacional. Desde esa perspectiva, el Congreso incidió preferentemente sobre las relaciones internacionales de la Península ibérica, planteando un análisis en perspectiva comparada de los fines de siglo en España y Portugal -Antonio Morales Moya-; una revisión sobre las claves del colonialismo español y portugués de fin de siglo — Juan José Carreras y Valentim Alexandre-; varios estudios paralelos sobre las políticas exteriores de España y Portugal -António José Telo, António Pedro Vicente e Hipólito de la Torre-; y una serie de trabajos monográficos sobre los intereses coloniales en Cuba - Ángel Bahamonde y José Gregorio Cayuela, Carlos Forcadell, José Luis Comellas, Mariano Esteban, Manuel Redero...- El Congreso analizó también la cultura en la Península ibérica a través de numerosas aportaciones

4 Los 98 ibéricos y el mar, vol 1: «La península Ibérica en sus relaciones internacionales»; vol. 2: «La cultura en la Península Ibérica»; vol 3: «El Estado y la política»; vol. 4: «La sociedad y la economía en la Península ibérica»; vol 5: «Comunicaciones. Los 98 ibéricos y el mar», Madrid, Sociedad Estatal Lisboa'98, 1998.

Hispania, LXI/2, núm. 208 (2001) 707-736 
- entre ellas las de Enrique Ucelay-Da Cal, José Carlos Mainer, José Manuel Sánchez Ron, Pedro Ruiz Torres, Celso Almuiña o José Andrés GallegoAbordó asimismo la evolución de los sistemas políticos en España y Portugal - José Varela, Carlos Dardé, Miguel Artola, Javier Tusell, Salvador Foner-, el despertar de los nacionalismos —Joâo Medina, Sisinio Pérez Garzón-, la evolución de la Administración -Alejandro Nieto, Luis da Silveira, Carlos Seco-, y las fuerzas políticas fuera del sistema - Manuel Suarez-Cortina, José Ferre Benimeli, Fernando Catroga, Julio Aróstegui-. Finalmente, el ciclo se cerró con análisis de la sociedad y la economía en la Península ibérica a través de varios parámetros: el crecimiento económico y el distanciamiento de la Europa desarrollada - Miriam Pereira, Pablo Martín Aceña, Pedro Tedde-; la situación demográfica - Teresa Rodrigues, Antonio Fernández, Germán Rueda_-; la sociedad agraria —-Antonio Miguel Bernal, Ramón Villares-; y la reforma social - Demetrio Castro, Feliciano Montero-. Como se puede comprobar, uno de los congresos más exhaustivos que reunió a buena parte de los representantes más significados de la historiografía actual.

En segundo lugar, la Universidad Complutense convocó un nuevo congreso como cierre de su reflexión colectiva sobre el 98, celebrado en Madrid en Noviembre de 1998. Sus frutos se reflejaron en un libro coordinado por Octavio Ruiz Manjón y Alicia Langa, Los significados del $98^{5}$. En él trataron de integrar perspectivas muy variadas en la reflexión histórica, desde la política a la literaria, desde la científica a la económica. La intención de los organizadores era poner el énfasis más allá del acontecimiento bélico y diplomático, e insistir en lo que el 98 tuvo de revulsivo y de referencia para una sociedad que, independientemente del desenlace de la guerra, experimentaba ya profundas tensiones y estaba sumida en un vigoroso debate sobre las vías para conseguir su modernización. Con ese propósito se trabajó en tres grandes líneas: vida política, economía-sociedad y vida intelectual. Quizás lo más significado del capítulo dedicado a la política sean las reflexiones de Antonio Elorza y de Borja de Riquer sobre la incapacidad del sistema político para aceptar una España plural desde los postulados del liberalismo, la crisis del Estado-Nación, y la respuesta de los nacionalismos periféricos ante tal situación; los análisis sobre política exterior de Javier Rubio y Juan Carlos Pereira; y los trabajos sobre política colonial referidos a Cuba y Puerto Rico - Elena Hernández Sandoica - y a Filipinas - Leoncio Cabrero- Especial interés y renovación presentan los estudios económicos presentados por Albert Carreras, Francisco Comín y Sergio Nasarre que inciden en la expansión que este sector experimentó en el fin de siglo. La sección más novedosa es la referente al ambiente intelectual, la educación, la ciencia y el pensamiento regeneracionista; en ella destacan los trabajos de Santos Juliá, Javier Tusell, Angel Isac, Serge Salaün y José Luis Peset, que subrayan la intensa de-

5 Ruiz MANJón, Octavio y LANGA, Alicia: Los significados del 98: la sociedad española en la génesis del siglo XX, Madrid, Biblioteca Nueva, 1999.

Hispania, LXI/2, núm. 208 (2001) 707-736 
manda social de transformación, lo cual se tradujo en importantes esfuerzos educativos, en avances científicos, y en el desarrollo de la cultura, las artes y la arquitectura. El libro se cierra con unos ensayos breves, entre los cuales destacan el de Ignacio Sotelo que reflexiona sobre la significación del 98 como hito histórico y sobre las consecuencias que tuvo para el devenir de la nación, subrayando cómo la incapacidad del régimen de la Restauración para evolucionar hacia una verdadera democracia e incorporar a las fuerzas ajenas al sistema favorecieron el trágico camino que acabó en la guerra civil; y el de Juan Pablo Fusi que plantea otra reflexión, mucho más optimista, sobre el florecimiento de la cultura española desde el final de siglo a las primeras décadas del XX.

En tercer lugar, vamos a culminar el ciclo de congresos reseñando el simposio internacional Después del 98: Identidad nacional, racial y social en Cuba, Espa$\tilde{n} a$, Filipinas y Puerto Rico, organizado por Josep M. ${ }^{a}$ Fradera en la Universitat Pompeu Fabra en Noviembre de $1999^{6}$. Muchos de sus debates - no todos, ni tampoco las interesantes discusiones que generaron las conferencias - se reflejaron en el $\mathrm{n}^{\circ} 2$ de la revista Illes e Imperis. En la reunión se plantearon temas diferentes y se escucharon conclusiones novedosas respecto a lo que habían sido los demás coloquios. Se partía de la idea de que no tenía sentido revisar la crisis de 1898 sin recordar los vínculos entre España y las sociedades dominadas que entonces se separaron. El propósito era analizar y debatir, a partir de un enfoque comparativo, los procesos de descolonización y de formación de nuevos marcos nacionales en Cuba, Filipinas y Puerto Rico después de las guerras de 1895-1898, así como sus repercusiones en España. El acento se puso precisamente en la ampliación de las perspectivas, superando una reflexión española y para españoles sobre el tema. Se trataba de repensar el sentido del legado colonial español, y de estudiar la complejidad de las construcciones nacionales a partir de ese marco colonial, desde enfoques transnacionales. En las conclusiones destacaba la diversidad de las sociedades coloniales, en las que se entrecruzaban grupos sociales, razas, religiones e intereses diferentes que dificultaron la definición de una identidad común y la elaboración de un proyecto nacional integrado. José Arcilla, Norman Owen y Josep M. Delgado analizaron la situación filipina. Astrid Cubano y Francisco Scarano la realidad puertorriqueña. Rebecca Scott, Jorge Ibarra y Michael Zeuske —entre otros- la complejidad cubana. Enric Ucelay-Da Cal y Christopher Schmidt Nowara cerraron el ciclo con interpretaciones generales sobre los distintos modelos coloniales. En resumen, una interesante reflexión sobre la realidad colonial y la construcción nacional más allá de los parámetros al uso.

6 Illes $i$ Imperis. Estudies d'historia de les societats en el món colonial i post-colonial, Universitat Pompeu Fabra, "Después del 98: Identidad nacional, racial y social en Cuba, España, Filipinas y Puerto Rico», 2 (1999), 7-219. 


\section{- Seminarios}

Entre los muchos seminarios celebrados, quizás el más significativo de todos ellos - y el único en el que nos vamos a detener- haya sido el organizado por la Fundación Pablo Iglesias, España y el 98, que fue coordinado por Rosa Pardo. En él, a lo largo de dos años, se realizó una completa revisión de la España finisecular a través de cuatro prismas: primero, la perspectiva social e institucional de la crisis, en la cual Carlos Dardé y Javier Moreno trataron de los partidos políticos; Borja de Riquer y Ludge Mees de los nacionalismos catalán y vasco; Pere Gabriel, Carlos Seco y Nuria Sales de la protesta social ante la guerra; y Manuel Pérez Ledesma y Mariano Esteban desarrollaron la actitud de la opinión pública española ante el 98. En segundo lugar, se abordó la perspectiva ideológica, y en ella José Varela Ortega, Javier Varela y Jon Juaristi plantearon el tema del regeneracionismo; José Alvarez Junco reflexionó sobre el nacionalismo español; y Andrés de Blas, Santos Juliá, Francisco Laporta y José Carlos Mainer trataron del ambiente y el pensamiento intelectual de la época. En tercer lugar, se estudió la perspectiva internacional de la crisis, con sendas exposiciones sobre la política colonial en Cuba - Inés Roldán-, en Puerto Rico - Astrid Cubano- y en Filipinas - M. $^{\text {a }}$ Dolores Elizalde-; Rosario de la Torre, Fernando García Sanz e Hipólito de la Torre trazaron las coordenadas de la coyuntura internacional; y Antonio Santamaría y $M{ }^{a}{ }^{a}$ Dolores Elizalde presentaron respectivamente las visiones de la crisis desde Cuba y desde Estados Unidos. Finalmente, en cuarto lugar, se trató de la perspectiva económica del 98, con intervenciones de Gabriel Tortella, Pedro Fraile y Jordi Maluquer sobre la economía española en el marco internacional; Francisco Comín, Pablo Martín Aceña y José Luis García Delgado hablaron de la hacienda, la política monetaria y el nacionalismo económico; Albert Carreras, Pedro Tedde y Angel García Sanz analizaron la estructura económica finisecular -industria, banca y agricultura-; el ciclo finalizó con una conferencia de Mercedes Cabrera y Fernando del Rey sobre la movilización empresarial en torno a 1898. Lástima que esos trabajos no se reunieran en un volumen que agrupara todas las aportaciones. Hubiera sido un libro clave para entender la España de fines del XIX y comienzos del XX.

\section{- Publicaciones colectivas}

Las publicaciones colectivas han sido también numerosas y especialmente valiosas. Entre ellas vamos a señalar - sólo- cinco que consideramos de especial significación. En primer lugar, vamos a hablar de uno de los libros -a nuestro juicio- más interesantes en este repensar el 98: Más se perdió en Cuba. España, 1898 y la crisis de fin de siglo, editado por Juan Pan Montojo ${ }^{7}$. Esta obra

7 Pan-Montojo, Juan, coord.: Más se perdió en Cuba. España, 1898 y la crisis de fin de siglo, Madrid, Alianza, 1998.

Hispania, LXI/2, núm. 208 (2001) 707-736 
une el acierto de su perspectiva general, con la originalidad en los planteamientos de cada uno de los trabajos y una lograda coherencia entre ellos, concebidos desde un principio desde una perspectiva común y armonizada, lo cual se deja notar en el resultado final.

En la introducción, Pan Montojo caracteriza el fin de siglo español y lo inserta en el marco internacional de su tiempo. Rebate el 98 en tanto que acontecimiento singular español, para situarlo en la inflexión del fin de siglo europeo, subrayando los rasgos compartidos por los países occidentales. Si el 98 adquirió en España una significación especialmente dramática no fue porque fuera una nación diferente ni especialmente atrasada respecto a la media, sino porque la derrota se vivió como la manifestación del fracaso del proyecto nacional español. A pesar de ello, 1898 no significó una crisis fundamental en casi ningún campo: «La derrota no cambió el Gobierno, ni la composición de las Cortes, ni el titular de la Corona, ni mucho menos la Constitución o el sistema de partidos: el régimen de la Restauración no conoció en su entramado institucional un antes y un después del 98». Los factores que incidieron en la evolución política que experimentó el país en torno a 1898 se debieron más a un cambio generacional en la dirección de los partidos, al acceso al trono de Alfonso XIII cuando alcanzó la mayoría de edad, a la consolidación de nuevas organizaciones políticas, y a transformaciones estructurales de largo plazo, que a unos efectos directamente provocados por el 98. La mayoría de los procesos de cambio ya estaban en marcha desde los años noventa, e incluso desde antes. La pérdida de las colonias tampoco provocó la bancarrota del Estado ni inauguró una época de depresión originada por la destrucción de los favorables intercambios comerciales con Ultramar. Las tendencias en economía se mantuvieron estables. Ni siquiera en el campo de la creación literaria y artística fue el Desastre un punto de ruptura. Las innovaciones estilísticas y formales se habían iniciado en la década anterior a 1898. ¿Estuvo entonces desprovisto de consecuencias el abrupto final del imperio español?, se pregunta Pan Montojo. Ciertamente no. La posición internacional de España se vio alterada, al tiempo que lo hizo su estructura territorial. Ultramar desapareció como elemento de la vida política española. El horizonte colonial se circunscribió al Norte de Africa. Además, el trauma bélico precipitó una crisis en las conciencias y en los discursos, aunque los problemas ya estaban latentes en las dos décadas finiseculares. Las críticas de los intelectuales, de la clase política, de la prensa, o de determinados movimientos sociales incrementaron las fisuras del régimen liberal, y contribuyeron a deslegitimar el proyecto nacional y a subrayar la necesidad de emplazarlo sobre bases diferentes. Se generalizaron las percepciones de crisis y decadencia, y frente a ellas se subrayó la necesidad de la regeneración, el planteamiento de nuevas soluciones. Tal fue el principal efecto del $98^{8}$.

8 Pan-Montojo, Juan: «Introducción. ¿98 o fin de siglo?», pp. 9-28.

Hispania, LXI/2, núm. 208 (2001) 707-736 
Desde ese planteamiento programático, el libro reúne, entre otros artículos, un análisis sobre las colonias realizado por Christopher Schmidt-Nowara, en el cual caracteriza al imperio español de fines del XIX, cuestionando su imagen obsoleta y subrayando por contra los muchos intereses que todavía tenía España en sus territorios ultramarinos, y el impulso que éstos experimentaron en las últimas décadas del siglo. Realiza también un análisis muy certero de la situación de Cuba, Puerto Rico y Filipinas, conjungando su triple realidad nacional - en tanto que nuevas naciones en proceso de afirmación-, colonial e internacional, para acabar señalando cómo incidió la guerra hispano-norteamericana en la evolución natural de estos archipiélagos?.

Manuel Pérez Ledesma plantea una reflexión sobre la manera que afectaron a la sociedad española las guerras de Cuba y Filipinas y la derrota ante Estados Unidos. En ella señala las diferentes reacciones de distintos sectores sociales a lo largo del conflicto, contrastando tres actitudes: la exaltación patriótica y la labor movilizadora de la mayor parte de la prensa, de la Iglesia y de los republicanos; la oposición a la contienda mostrada por los reservistas, los socialistas, los federalistas o las mujeres afectadas por la marcha de sus familiares; y finalmente la pasividad y la resignación ante la guerra y ante sus consecuencias patente en determinados momentos y sectores ${ }^{10}$.

Juan Pro analiza la política en tiempos del Desastre, señalando cómo los problemas del régimen vigente - falseamiento del sistema parlamentario representativo, límite incierto de las prerrogativas regias, disidencias internas en los partidos dinásticos, incapacidad para ampliar las bases sociales y para responder a las demandas de nuevos grupos sociales y políticos- provocaron a la larga la crisis del sistema. Resalta que 1898 representó la ocasión para una reflexión profunda sobre las lacras existentes y sobre las posibilidades para superarlas - qué motivos habían conducido al debilitamiento español, y posibles fórmulas para salir de él-. El fracaso para llevar a la práctica las propuestas regeneracionistas y para democratizar la vida política facilitó los levantamientos militares - dictadura de Primo de Rivera, guerra civil- que quisieron imponer alternativas dictatoriales para la necesaria regeneración de España ${ }^{11}$.

Finalmente, José Alvarez Junco plantea que 1898 se vivió con tal dramatismo porque se contempló como la manifestación del fracaso del proyecto nacional español gestado a lo largo del siglo XIX. La derrota ante Estados Unidos se convirtió en el «Desastre» precisamente por el fervor nacionalista imperante. En esa centuria se habían ido afirmando en toda Europa las identidades nacionales y España no era una excepción. Al finalizar el siglo, los caracteres de esa identidad estaban ya bastante definidos: la publicística de la época proclamaba que sobre un territorio privilegiado se asentaba un pueblo católico y monárquico; inclinado por naturaleza hacia el honor, la caballerosidad o el des-

9 SCHMIDT-NOWARA, Christopher: «Imperio y crisis colonial», pp. 31-90.

10 PÉrez-Ledesma, Manuel: «La sociedad española, la guerra y la derrota», pp. 91-150.

11 Pro RuIZ, Juan: «La política en tiempos del Desastre», pp. 151-260. 
prendimiento; de probada belicosidad, capaz de morir antes que rendirse; y que como prueba de su pertenencia al grupo de naciones privilegiadas, era dueño de posesiones coloniales que se extendían por el Caribe, el Pacífico y Africa. En ese clima de exaltación se produjo la derrota en la guerra hispanonorteamericana y la pérdida de las colonias, que se entendió, no como una inferioridad bélica coyuntural, sino como una manifestación del grave deterioro del ente nacional. El Desastre de 1898 se convertiría así, a ojos del autor, en un claro caso de percepción sobredimensionada de unos acontecimientos, de limitada importancia en sí mismos, pero vividos como una desgracia colectiva de proporciones cataclísmicas. Lo cual generó una angustiada reflexión sobre la esencia de ser español, sobre la degeneración de la raza y sobre las fórmulas para superar tal situación ${ }^{12}$.

En el libro España en 1898. Las claves del 98, Pedro Laín Entralgo y Carlos Seco Serrano plantean el 98 como la fecha que marcó la pérdida de las colonias en un desastre bélico; que dio nombre a una generación de escritores fundamental para la historia de la literatura y del pensamiento españoles; y que inició una dramática etapa en la vida política española no resuelta hasta la Transición postfranquista. Los autores reunidos por los editores en este volumen realizan un profundo análisis de aquella España «a la vez insatisfactoria y prometedora», señalando que tras el 98, y a pesar de los intentos regeneracionistas más logrados en el campo de la economía-, no se supieron resolver los problemas políticos planteados en el fin de siglo, los cuales permanecieron vigentes en la sociedad española hasta fechas muy recientes. La aportación más interesante de la obra se produce en las reflexiones sobre la sociedad, el ambiente intelectual, y la evolución científica y artística de la época, un momento especialmente rico para la cultura española. Destacan sus autores el florecimiento de «una generación de sabios» apenas iniciada la Restauración —el médico Ramón y Cajal, el ingeniero Torres Quevedo, el fisiólogo Gómez Ocaña, el historiador Altamira, el ensayista Menéndez Pelayo, el cirujano San Martín, el arabista Ribera, los novelistas Galdós y Clarín, el educador Giner de los Ríos, el pintor Sorolla...-; la aparición sucesiva de las generaciones del 98, 14 y 27; la transformación de la enseñanza bajo el impulso del krausismo y de la Institución Libre de Enseñanza; la creación de instituciones dinamizadoras de la vida cultural, como la Junta para la Ampliación de Estudios. Hay un análisis de la creación literaria de la época en la poesía, la novela, el teatro y las literaturas regionales; de la evolución artística de la arquitectura, la pintura y la escultura en torno al 98; de las consecuencias del 98 en la conciencia colectiva y la reacción regeneracionista; cerrándose el libro con una encendida defensa de la existencia de una generación del 98, pormenorizadamente caracterizada por Laín ${ }^{13}$.

12 Alvarez Junco, José: «La nación en duda», pp. 405-476.

13 Laín EnTralgo, Pedro y Seco Serrano, Carlos, eds.: España en 1898. Las claves del Desastre, Barcelona, Galaxia Gutenberg-Círculo de Lectores, 1998. 
Revista de Occidente dedicó un monográfico al tema, 1898, ¿desastre nacional o impulso modernizador? que funcionó más como un libro colectivo bien trabado que como un conjunto de artículos coincidentes en el número de una revista ${ }^{14}$. A cada autor se le solicitó que trabajara sobre un tema que se consideró necesario plantear en relación con la pregunta suscitada. El punto de partida del volumen - coordinado por la autora de estas páginas - incidía en la perspectiva desdramatizadora del 98, subrayando la necesidad de superar la visión catastrofista del Desastre. Desde esa posición, pretendía calibrar hasta qué punto 1898 provocó situaciones de crisis en diferentes parámetros de la vida nacional, y cuestionar si, por contra, era posible contemplar al 98 como un detonante político, económico, social e intelectual que hizo avanzar a España en el camino hacia la modernización.

Sin minimizar los hechos, se reconocía 1898 como una rotunda derrota militar frente a una potencia no europea, los Estados Unidos, que conllevó la pérdida de las últimas colonias en las Antillas y en el Pacífico. Tal circunstancia supuso un duro trance para el país y —en determinados círculos: políticos, intelectuales, militares, clases ilustradas, prensa- provocó una conciencia de crisis, la sensación de no saber los límites que podía tener el enfrentamiento y de que se había perdido el control sobre el destino nacional. A raíz del 98 se extendió en España el sentimiento de que la nación había entrado en agonía, era la España sin pulso, la manifestación de la decadencia patria, el símbolo de la degeneración de la raza. Fue el pesimismo generalizado de los coetáneos el que originó la idea del desastre. Sin embargo, esa visión catastrofista no se correspondía totalmente a la realidad, porque la crisis militar y colonial vivida por España no fue tan diferente a las sufridas por otros países europeos en la misma época, y además las repercusiones que ocasionó fueron limitadas. Tampoco la nación estaba tan atrasada ni era tan singular como los coetáneos creyeron. Por contra, España podía incluirse en la normalidad de su entorno, con los problemas, las limitaciones y las ventajas de una potencia media en pleno proceso de evolución política y de crecimiento económico. El clima de crisis y pesimismo originado por el 98 produjo un profundo replanteamiento de lo que era y de lo que debía ser España. Sin embargo, no provocó una quiebra del sistema político, una revolución social ni una crisis económica. Lo que hizo fue impulsar una actitud reformista y una voluntad de cambios: ante lo acaecido la consigna fue mejorar, sanear, modernizar España. Para evitar el colapso del régimen se consideró necesario reformarlo. Es cierto que ese espíritu no nació en 1898, que se encontraba ya presente en intelectuales y políticos desde los años 60 y 70 del siglo XIX, y que la intención de reconstruir el país estaba en la base misma de la Restauración canovista. Ahora bien, en esa línea, 1898 supuso un formidable revulsivo que imprimió un nuevo impulso al movimiento regeneracionista y

14 Revista de Occidente, Monográfico 1898, ¿desastre nacional o impulso modernizador?, n $202-$ 203, (1998).

Hispania, LXI/2, núm. 208 (2001) 707-736 
provocó una efervescencia de debates cuyo objetivo era la modernización de España. Gracias a ello se reformaron la administración, la educación, la sanidad, la política económica, la posición internacional, las obras públicas. A pesar de lo cual, no se alcanzó el grado de renovación de la vida pública deseada por los regeneracionistas más progresistas. No se consiguió democratizar la política. No se corrigió el reiterado fraude electoral. No se incorporaron al proyecto nacional las nuevas fuerzas sociales ni las propuestas políticas que ya habían cristalizado en ese fin de siglo. Ello conduciría inexorablemente, décadas más tarde, al colapso del sistema ${ }^{15}$. Con tales premisas como referente y horizonte, en el volumen se revisan la existencia o no de crisis y de regeneración en distintos sectores.

José Varela Ortega analiza el régimen político de la Restauración, subrayando los avances políticos que posibilitó, reseñando los problemas que planteó, y señalando por encima de ellos —éxitos y fracasos - la fortaleza que demostró ante circunstancias tan adversas como el $98^{16}$.

Vicente Cacho Viu establece un paralelismo entre la crisis francesa de 1870 y la española de 1898 - dos países europeos en retroceso que con ocasión de un fracaso militar se cuestionan su propia identidad-, y defiende que el proceso de modernización estimulado por la derrota de Francia en 1870 se convirtió en punto de referencia para la minoría intelectual española de 1898. Sin embargo, señala cómo en España el impacto emocional del 98 se desvaneció con notable rapidez, y los intelectuales hubieron de contemplar con desencanto que ni el régimen de la Restauración ni la sociedad en general daban muestras de una conmoción profunda que hiciese presagiar una regeneración a corto plazo. Distingue las reacciones ante el 98 de dos generaciones de intelectuales, aquellos que lo vivieron en su madurez, mucho más pesimistas en sus discursos, y los que lo afrontaron en su juventud, los cuales trasmitían mayor esperanza en el porvenir y proponían la búsqueda de nuevas vías de modernización ${ }^{17}$.

José Carlos Mainer reflexiona sobre la crisis en el pensamiento de fin de siglo con una nota de optimismo. Sin aquellos debates tan sentidos, tan apasionados, tan pedagógicos, sería difícil entender la evolución intelectual y política de España. A raíz de 1898 nacieron muchas de las corrientes que conformaron la España del siglo $\mathrm{XX}^{18}$.

En esa misma línea insiste Francisco Villacorta, que nos proporciona las claves de la disposición intelectual con que se asumió la crisis del liberalismo de fines del XIX y nos muestra nuevos procesos de mediación social y la consolidación de una clase profesional que influiría en el futuro de la nación ${ }^{19}$.

15 Elizalde, Ma Dolores: «Presentación», pp. 5-9

16 VARELA ORTEGA, José: «La España política de fin de siglo», pp. 43-77.

17 CACHO VIU, Vicente: «Francia, 1870-España, 1898», pp. 9-42.

18 Carlos Mainer, José: «La crisis intelectual del 98: de Rudin a lord Chandos», pp. 112-130.

19 VillacoRTA, Francisco: «fin de siglo: crisis del liberalismo y nuevos procesos de mediación social», pp. 131-148.

Hispania, LXI/2, núm. 208 (2001) 707-736 
Manuel Espadas y Rosario de la Torre revisan la política exterior española en torno al fin de siglo, caracterizada por el dilema vivido por una pequeña potencia rica en dominios coloniales que no tenía medios para defender, y que oscilaba entre un deseado recogimiento internacional y una necesaria búsqueda de aliados. Enmarcan la crisis del 98 en el contexto de la expansión de las grandes potencias que llevó a un nuevo reparto del mundo en zonas de influencia, y analizan cómo se enfrentó - y sufrió - España esas nuevas circunstancias. Señalan también que, a raíz de 1898, se reorientó la política exterior española, produciéndose un viraje desde la anterior inclinación pro-germánica hacia el alineamiento con Francia y Gran Bretaña, que serían en el nuevo siglo las valeedoras de su posición internacional y las garantes de la integridad de su territorio ${ }^{20}$.

Juan Pan Montojo estudia la evolución de la economía española en torno a 1898 , señalando su incardinación en las mismas tendencias dominantes en otros países europeos en aquél momento: crisis agraria y transformación de la sociedad rural, crecimiento y concentración de la industrialización, replanteamiento de los términos de la «cuestión social», con la peculiaridad de que en los tres sectores la situación española se vivió de forma más amortiguada que en otros países europeos. En ninguno de esos terrenos se apartaba España en exceso de su entorno. Sin embargo, el 98 generó una sensación de atraso relativo y creciente en el campo económico y por ello los regeneracionistas exigieron una nueva política económica que hiciera posible el desarrollo de la nación. Lo cual, según Pan Montojo, a pesar de los esfuerzos de Fernández Villaverde, no se consiguió plenamente. La eficacia de los diversos regeneracionismos sobre la política económica fue casi exclusivamente retórica ${ }^{21}$.

Jordi Maluquer de Motes realiza un brillante y didáctico análisis de las consecuencias económicas de las guerras de 1898. Con una conclusión muy clara: las guerras y la pérdida de las colonias no originaron una crisis en la economía española. Para demostrar tal aseveración precisa los efectos de la coyuntura bélica sobre la población y sobre la economía, cifrando los recursos comprometidos en las guerras (200.000 hombres movilizados, en torno a 440.000 muertos) (medios económicos para proporcionar los elementos imprescindibles para llevarlos a cabo: 3.500 millones de pesetas - la tercera parte del PIB español de un año de la época-). Señala las formas que se emplearon para financiar las guerras coloniales: mediante la creación de dinero a base de generar presiones inflacionistas, de crear nuevos impuestos, de recargar algunos ya existentes y, sobre todo de emitir deuda pública - punto al que dedica una especial atención-. Explica con detenimiento la formulación de las deudas de la guerra a través de empréstitos garantizados por diversas modalidades: distintas fuentes de rentas - entre ellas la de aduanas_-, el tesoro de Cuba y el de Filipinas. Diferencia también quiénes suscribieron los empréstitos, superando incluso con

20 EsPadAs BuRgos, Manuel: «La dimensión europea del 98: una soledad anunciada», pp. 149167. Rosario de la Torre, «Una crisis que rectificó la orientación de la política exterior», pp. 168-182.

21 PAN MONTOJO, Juan: «Economía y política del Desastre», pp. 250-263. 
su entusiasta respuesta las necesidades del tesoro. Señala su monto -11.500 millones de pesetas a fines de 1898-. Describe las fluctuaciones en el mercado de la deuda y las causas de tales variaciones -el impacto del devenir de la guerra-. Finalmente, explica la confianza en el sistema gracias a su buen funcionamiento y a la escrupulosa puntualidad en el cumplimiento de los pagos por parte del Estado, que consiguió liquidar toda la deuda. El arreglo general de la deuda, la reforma tributaria y el equilibrio presupuestario logrado por Fernández Villaverde consiguieron que desde 1899 y hasta 1909, sin interrupción, el ejercicio presupuestario se saldara con permanente superávit. A partir de 1897 y hasta 1903 hubo un crecimiento del PIB. Las exportaciones a las colonias no sólo no se interrumpieron, sino que en los años inmediatos a la guerra incluso aumentaron. La deflación de la peseta originada por la guerra tuvo como efectos beneficiosos frenar las importaciones, aumentar las exportaciones. Se inició también uno de los ciclos inversores más brillantes de la época contemporánea -incluida una significativa repatriación de capitales coloniales-. Todo lo cual hace concluir a Maluquer que, aunque las guerras siempre tienen efectos fatales, en el caso del 98, y atendiendo a su financiación y a sus consecuencias económicas, nada justifica el término "desastre». Por contra, como bien señala: «al terminar la guerra el dinero abundaba en España de un modo pocas veces visto» ${ }^{22}$.

Josep M. Fradera plantea una reflexión a largo plazo sobre la política colonial española en el siglo XIX, señalando su evolución a través del tiempo y los motivos por los que se fue transformando. Distingue una primera etapa de reajuste y adaptación a la nueva coyuntura surgida tras la independencia de los territorios de la América continental, en la cual se busca un nuevo reordenamiento político e institucional, se redefinen los incentivos económicos de cada territorio, y se establecen nuevas fórmulas fiscales. A partir de 1837 comenzaría una segunda etapa, en la cual se decide la expulsión de los diputados ultramarinos de las Cortes, se redactan las leyes especiales para los enclaves coloniales, y se reafirman las estructuras de poder metropolitano. No obstante, tales medidas no provocaron un inmediato rechazo por parte de las burguesía isleñas porque las autoridades coloniales consintieron el mantenimiento de una mano de obra esclava y organizaron unos sistemas fiscales que beneficiaban los intereses de esos grupos. Sin embargo, a largo plazo la situación resultaría insostenible. La incapacidad de la Metrópoli para incorporar las aspiraciones políticas y legales de las clases medias ilustradas y de las nuevas fuerzas sociales emergentes a la vida política del país llevarían a la quiebra de la relación. Paralelamente se fue produciendo un alejamiento en los intereses económicos peninsulares y ultramarinos. Todo ello provocó que a partir de 1868 se produjera una bifurcación en la evolución de la situación en Cuba y Puerto Rico, por un lado, y en Filipinas, por otro. Desde los años setenta en las Antillas se fue reafirman-

22 MALUQUER DE MOTES, Jordi: «Las consecuencias económicas de las guerras de 1898», pp. 264-277.

Hispania, LXI/2, núm. 208 (2001) 707-736 
do la creciente divergencia entre Metrópoli y colonias. Cuba emprende ya un imparable camino hacia la independencia del cual son conscientes las autoridades españolas a pesar de sus esfuerzos por retener las islas. En Filipinas, por contra, se renueva el interés en la administración colonial y se refuerzan las inversiones en el archipiélago, ignorando la existencia también en aquellos enclaves de una élite filipina cada vez más inmersa en un proceso de reafirmación nacional y de desarrollo autóctono de su economía ${ }^{23}$.

Complementando ese marco general, Elena Hernández Sandoica, Astrid Cubano y $\mathrm{M}^{\mathrm{a}}$ Dolores Elizalde realizan sendos análisis sobre la situación en Cuba, Puerto Rico y Filipinas en torno al fin de siglo, y sobre el decisivo impacto del 98 en estos territorios. En ellos afirman la función que desempeñaban cada una de estas islas en la configuración del Estado español, subrayan los lazos entre los intereses coloniales y los grupos políticos de la Restauración, y destacan cómo se fue produciendo la divergencia entre los peninsulares y las poblaciones de las antiguas colonias. Reflejan la existencia, en cada una de esas islas, de unas sociedades indígenas pujantes y dinámicas, con objetivos nacionales ya definidos. La fuerza de los procesos independentistas ya en marcha en el fin de siglo era tal que hubiera conducido inevitablemente a la ruptura entre metrólopi y colonias. También la evolución económica alejaba progresivamente los intereses de las colonias de la economía española. Pero la independencia de los territorios ultramarinos hubiera podido producirse de manera escalonada y menos tan traumática que como sucedió en 1898 con la intervención de los Estados Unidos ${ }^{24}$. El volumen se cierra con sendos estudios sobre la imagen de Estados Unidos en España y viceversa, elaborados respectivamente por Rosario Sevilla y Rafael Sánchez Mantero ${ }^{25}$.

Bajo el impulso de la Fundación Ortega y Gasset, y la dirección de José Varela Ortega, se publicó el libro Imágenes y ensayos del $98^{26}$. En el prólogo Raymond Carr planteaba la significación del 98, señalando que si bien una derrota nacional en una guerra puede derrumbar al régimen político que ha llevado a la nación al desastre, en 1898 no ocurrió tal cosa en España a pesar de la visión tan pesimista con que se encararon los hechos. Carr señala varios factores que contribuyeron al mantenimiento del sistema político de la Restauración. En su opinión, los restos del imperio español en Cuba, Puerto Rico y Filipinas constituían un ejemplo claro de «sobre-extensión del imperio», una

23 Fradera, Josep M.: «La política colonial española del siglo XIX. Una reflexión sobre los precedentes de la crisis de fin de siglo», pp. 183-199.

24 HeRNÁNDEZ SANDOICA, Elena: «Escenarios ultramarinos del 98: Cuba antes de la autonomía», pp. 200-212. Astrid Cubano, «Reflexiones en torno al 98 en Puerto Rico y la crisis del colonialismo español», pp. 213-223. $\mathrm{M}^{a}$ Dolores Elizalde, «Filipinas, 1898», pp. 224-249.

25 SEvilla, Rosario: «España y Estados Unidos: 1898, impresiones de un derrotado», pp. 278293. Rafael Sánchez Mantero, «El 98 y la imagen de España en los Estados Unidos», pp. 294-309.

26 VARELa OrTega, José, ed.: Imágenes y ensayos del 98, Valencia, Fundación Cañada Blanch, 1998.

Hispania, LXI/2, núm. 208 (2001) 707-736 
responsabilidad política imposible de mantener. En las colonias se desarrollaban, además, unas guerras de liberación nacional que por su índole tendrían como resultado lógico la derrota del poder colonial. Junto a ello, en esos territorios España hubo de enfrentarse a las ambiciones imperialistas de uno de los grandes poderes económicos del momento, los Estados Unidos. El resultado de esos procesos era, pues, -a su juicio- inevitable ${ }^{27}$.

Los gobernantes españoles eran conscientes de que la guerra contra los norteamericanos sólo podría acabar en derrota, pero por razones políticas decidieron que sería más positivo para la estabilidad del Régimen perder en batalla los territorios coloniales que cederlos de manera voluntaria, lo cual podría originar un levantamiento militar y el estallido de una opinión pública enfervorecida por la retórica patriótica y convencida de la victoria dadas las características patrias y raciales - de nuevo el mito de los españoles invencibles, el león hispánico frente al cerdo yanqui-. Esa falta de preparación para la derrota fue la que originó una explosión de verdadera crisis en la conciencia nacional, que tomó la forma de regeneracionismo. Matiza Carr que se podría argumentar que. en realidad la derrota simplemente agudizó las distintas críticas del sistema político de la Restauración previamente existentes que provenían de sectores catalanistas, republicanos, socialistas, carlistas y anarquistas. Sin embargo, los regeneracionistas de 1898 aportaron además un programa de reformas y trataron de llevar a la práctica un proyecto concreto de modernización del país. El problema fue que sus propuestas no consiguieron movilizar a las masas ni consolidar una alternativa al sistema existente. Sin capacidad para reformarlo y sin poder para derrumbarlo a través de una alternativa viable, las voces críticas, poniendo de relieve las limitaciones del modelo político, socavaron su legitimidad. A pesar de sus imperfecciones, el pacto y el turno en el gobierno era el que había proporcionado estabilidad al régimen de la Restauración. A partir de las críticas recibidas, de la fragmentación de los partidos dinásticos, del desarrollo de una nueva sociedad civil, y de la aparición de nuevas fuerzas sociales no incorporadas a la vida pública, España se encontró con un problema de gobernabilidad. El peligro era que se produjera, como de hecho ocurrió, la aparición de un cirujano de hierro que pretendiera poner fin a los males de la patria. La amarga consecuencia a largo plazo de la derrota de 1898 fue la reaparición del ejército como árbitro de la vida política.

En el libro hay importantes contribuciones. Carlos Dardé, desde un profundo conocimiento del tema que aborda, presenta una valoración política de la Restauración, en la que estudia las inspiraciones del sistema político construido durante ese período, señala sus características principales, y realiza un balance de sus resultados —éxitos y fracasos_- ${ }^{28}$. Rosario de la Torre reflexiona

27 CARR, Raymond: «Prólogo», pp. 9-14.

28 DARDÉ, Carlos: «Antecedentes: la Restauración, 1875-1902. El significado de una etapa histórica», pp. 15-40.

Hispania, LXI/2, núm. 208 (2001) 707-736 
sobre la diplomacia del conflicto. Expone las características de las relaciones internacionales del fin de siglo y el papel desempeñado por España en aquel contexto. Estudia la evolución de la posición norteamericana ante la crisis cubana y la progresiva inclinación en favor de una intervención en la isla; las actitudes de las potencias europeas ante el conflicto hispano-norteamericano; y finalmente aborda las negociaciones que condujeron a la paz de París ${ }^{29}$. Hay también una interesante aportación de Fernando Puell de la Villa sobre el papel desempeñado por el Ejército en la administración colonial, en las guerras de Cuba y Filipinas, y en el conflicto norteamericano ${ }^{30}$.

Inman Fox esboza el transfondo intelectual del 98 a través de una serie de rasgos: la transformación de la sociedad civil; la aparición de una nueva clase de intelectuales con preocupaciones nacionales; la dinámica entre clericalismo y anticlericalismo; la revalidación de la cuestión social; los anhelos autonomistas de Cataluña y el País Vasco; la influencia de instituciones como el Ateneo o la Institución Libre de Enseñanza, que sirven de catalizadores de inquietudes intelectuales. Analiza también el pensamiento de un grupo de escritores e intelectuales que en torno a 1898 expresaron una común preocupación por el "problema de España» y propusieron posibles soluciones políticas, sociales y culturales en un contexto europeo, debatiendo sobre la génesis y evolución de la «generación del 98»31.

Carlos Malamud analiza las razones por las cuales, una vez independizada la América continental, se mantuvo la relación colonial entre España, Cuba y Puerto Rico. A partir de ese planteamiento hace un recorrido por las relaciones entre metrópoli y colonias, estudiando cómo, paulatinamente se alejaron sus respectivos intereses políticos y económicos en un proceso que culminaría en la reivindicación de la independencia, objetivo que se vería condicionado por la intervención de los Estados Unidos ${ }^{32}$. De forma paralela, M. ${ }^{a}$ Dolores Elizalde presenta un balance sobre las Filipinas de fin de siglo, definidas por tres factores: la administración colonial, la afirmación del nacionalismo filipino y los intereses internacionales. Sobre esa triple realidad se superpusieron las ambiciones manifestadas por los Estados Unidos durante la guerra hispano-norteamericana, que conllevaron el consecuente cambio en la soberanía sobre las islas ocurrido en $1898{ }^{33}$. En un tercer artículo de carácter colonial, Celso Almunia revisa la actitud de la opinión pública ante la pérdida de las colonias, a través de un cuadro sobre la prensa del momento - periódicos, agencias, marco legal para las publicaciones, medios técnicos, política informativa, lectores, etc-34.

29 DE LA TORRE, Rosario: «La diplomacia del conflicto», pp.41-74.

30 Puell de la Villa, Fernando: «Cara y cruz del «Desastre» militar», pp.75-116.

31 Fox, Inman: «El trasfondo intelectual del 98», pp. 117-150.

32 Malamud, Carlos: «El 98 de Cuba y Puerto Rico», pp. 151-174.

33 Elizalde, M.a Dolores: «El 98 filipino», pp. 175-204.

34 Almuiña, Celso: «La opinión pública española ante la pérdida del imperio colonial. De Zanjón al Desastre, 1878-1898», pp. 205-253.

Hispania, LXI/2, núm. 208 (2001) 707-736 
El libro se cierra con dos textos enjundiosos sobre las consecuencias del Desastre. En el primero de ellos, José Varela Ortega reflexiona sobre los motivos por los que Cuba permaneció bajo soberanía española a lo largo del XIX y sobre las razones por las que se prefirió ir a la guerra antes que ceder voluntariamente la isla a la presión norteamericana. Plantea luego que, cuando se perdió la guerra, la derrota se vivió como un problema nacional que genero una extensa reflexión sobre los males de la patria y sus posibles soluciones. Sin embargo, la Restauración fue capaz de digerir la derrota - a tal respecto hace una interesante disquisición sobre los méritos y fracasos del sistema político-, aunque se mostró incapaz de incorporar las nuevas propuestas. A pesar de ello la influencia de las ideas regeneracionistas tuvieron una honda y prolongada influencia tanto en el plano político como en el filosófico que puede rastrearse hasta nuestros días ${ }^{35}$.

Finalmente, Juan Pablo Fusi nos habla del legado del 98 señalando los problemas que condujeron a la defenestración de aquel régimen político. 1898 puso en evidencia la necesidad de cambiar el sistema. Se trataba de llevar a la práctica el programa de modernización propuesto por los regeneracionistas. Fracasados los sucesivos intentos para hacerlo realidad, se abrió una etapa sin horizontes que sumió al régimen liberal oligárquico en un proceso de progresivo anquilosamiento, frustrándose la, por otra parte, nada remota posibilidad de ser refundado. Fallaron los partidos, falló la Corona en una equivocada línea intervencionista, falló la apertura a nuevas fuerzas sociales, falló la democratización. La consecuencia fue el golpe militar, que quebró cinco décadas ininterrumpidas de tradición parlamentaria dentro del liberalismo constitucional. Se volvía a poner en marcha el mecanismo de la exclusión del adversario político, ahora con el agravante que implica la intervención de las armas en la política ${ }^{36}$.

Santos Juliá dirigió uno de los mejores y más amplios proyectos en torno al 98. A través de un método que no siempre es sinónimo de calidad, los suplementos dominicales de un periódico, planteó una Memoria del 98 en la que se revisaron muchos temas básicos con ánimo divulgador ${ }^{37}$. Pero ello no hizo bajar el listón. Tampoco lo logró la fragmentación semanal. Primero, porque participaron autores muy diversos que aportaron perspectivas diferentes y renovadoras. $Y$ segundo, porque se consiguieron pequeños artículos - obligados por la precariedad del espacio-, pero muchos de ellos de notable calidad. La mayor parte de los trabajos plantearon sus interpretaciones a largo plazo, no centrándolas tanto en lo ocurrido en 1898, sino explicando el contexto que condujo a esa coyuntura histórica, o las consecuencias posteriores que provocó. De tal manera, en el volumen resultante se revisó la política y la sociedad española de la Restauración

35 VARela ORTEGA, José: «Del Desastre y sus consecuencias», pp. 253-288.

36 PABLo FusI, Juan: «El legado del 98», pp. 289-302.

37 Juliá, Santos, dir.: Memoria del 98. De la guerra de Cuba a la Semana Trágica, Madrid, El País-Aguilar, 1997-1998.

Hispania, LXI/2, núm. 208 (2001) 707-736 
- Manuel Espadas Burgos, Miguel Artola, José Alvarez Junco, Javier Moreno, Fernando del Rey, Francisco Villacorta, Carlos Serrano ${ }^{38}$-.

En el campo colonial, autores como Moreno Fraginals hablaron de la evolución de Cuba a lo largo del XIX hasta desembocar en la definitiva divergencia de intereses entre peninsulares y cubanos. Astrid Cubano y Elena Hernández Sandoica se encargaron de resaltar las peculiaridades de Puerto Rico dentro del imperio español. Josep M. Delgado presentó una magnífica síntesis de las Filipinas de fin de siglo, incorporando muchas de las claves que están renovando las interpretaciones sobre aquel archipiélago ${ }^{39}$.

Respecto a los efectos de la guerra, Manuel Pérez Ledesma contrasta la conformidad y la indiferencia del grueso de la población española ante los resúltados de la guerra con la reacción de intelectuales y políticos, que fue para quienes realmente la derrota se convirtió en desastre. Ellos fueron quienes propusieron unas soluciones alternativas para sacar a la nación del marasmo en que se encontraba, sin que sus propuestas regeneracionistas tuvieran suficiente reflejo en la práctica política. Rafael Cruz aborda la reacción del ejército tras el 98 , señalando que a pesar de su mala situación - descrédito, exceso de hombres, falta de medios y objetivos - no se desvinculó de la vida política, lo cual posibilitaría su futura intervención en ella. Juan Pan-Montojo nos relata el drama de la repatriación con todas sus contradicciones - soldados enfermos y sin futuro frente a indianos enriquecidos dispuestos a repatriar sus capitales_ ${ }^{40}$.

En el terreno de la economía, Gabriel Tortella estudia la prosperidad adquirida por Cuba a lo largo del XIX y su progresiva inclinación hacia el mercado norteamericano, para incidir luego en las divergencias entre la economía cubana y la española que no podían conducir sino a la independencia. Pedro Fraile defiende - avalado por una buena serie de razones - que la pérdida de Cuba no fue desastrosa para la economía española. El descalabro no fue la pérdida de mercados cautivos, sino la consecuente adopción de una política nacionalista aislacionista, que inclinó la economía española hacia la autarquía, desaprovechando la ocasión de acercarla a la del resto de Europa. Leandro Prados analiza la evolución de la economía peninsular, señalando las tendencias del comercio exterior, subrayando su contribución al crecimiento económico del

38 ESPADAS Burgos, Manuel: «La trastienda de la Restauración», pp. 21-26. Artola, Miguel: «Partidos y elecciones», pp. 85-90. Álvarez JuNCO, José: «Los procesos de Montjuïc», pp. 69-74. MORENO, Javier: «Caciquismo y sufragio universal», pp. 92-93 DEL REY, Fernando: «De Cánovas a Sagasta», pp. 94-95. VILlACORTA, Francisco: «Una sociedad híbrida», pp. 30-31. SECO, Carlos: «iO todos o ninguno!, pp. 53-59.

39 Moreno Fraginals, Manuel: «La Guerra de los Diez Años», pp. 5-10; Guerra en la paz», pp. 37-42. Astrid Cubano, «los autonomistas de Puerto Rico», pp. 155-157. HeRnÁNDEZ SANDOICA, Elena: «La forja de la patria», pp. 149-154. DeLGADO, Josep M.: «El desastre de Cavite», pp. 117-125. RODRIGO, Martín: «La política naval antes del 98», pp. 126-127.

. 40 Pérez-Ledesma, Manuel: «Después del 98», pp. 181-186. CRUZ, Rafael: «La derrota y el ejército», 187-189. PAN-MONTOJO, Juan: «La repatriación», pp. 190-191. 
país. Finalmente, Francisco Comín valora positivamente las reformas económicas y presupuestarias emprendidas por Fernández Villaverde tras la guerra. En relación directa con las cuestiones económicas, Eloy Fernández Clemente estudia los planteamientos de los regeneracionistas, deteniéndose en las propuestas de la Unión Nacional. Tal perspectiva se completa con un análisis de Carlos Forcadell sobre la actitud de las Cámaras de Comercio tras la guerra, y una reflexión de Ricardo Robledo sobre los movimientos agrarios de protesta ${ }^{41}$.

Como no podía ser de otra manera, se dedica un capítulo al problema nacional, en el cual Andrés de Blas explica la refundación del nacionalismo español, señalando los factores que a su juicio contribuyeron a dinamizar tal proceso. En ese análisis, Javier Varela se detiene en la significación del nacionalismo económico. Antonio Morales y Mariano Esteban estudian la contribución del regeneracionismo al nacionalismo español. Joan Culla, Angel Duarte y Borja de Riquer señalan los rasgos del catalanismo emergente y Jon Juaristi, José Luis de la Granja y Javier Corcuera analizan los comienzos del nacionalismo vasco ${ }^{42}$.

Los últimos estudios sobre el 98 se centran en la revolución en las artes y en las letras, recreada a través de los prismas de Francisco Calvo Serrater y José Carlos Mainer ${ }^{43}$. Este ingente trabajo colectivo se cierra con varios estudios sobre la vida política en las primeras décadas del siglo XX, subrayando las muchas tensiones latentes por no haber sabido resolver los problemas planteados en el 98.

Quedan otros muchos libros colectivos dignos de estudio y revisión. No nos vamos a detener y a analizarlos en detalle, y ni siquiera a relacionarlos. Queremos sólo citar escuetamente tres más. En primer lugar, Tiempo del 98, editado por Roberto Mesa, con interesantes colaboraciones de Carlos Seco, Manuel Pérez Ledesma, Julián Companys, Laporta, Sánchez-Ron, Ynduráin o Pedro Laín, en el que destacan fundamentalmente los artículos de carácter cultural ${ }^{44}$.

41 Tortella, Gabriel: «Lo que se perdió en Cuba», pp. 197-202. Fraile, Pedro: «¿Fue realmente un desastre?», pp. 203-205. PRADOS, Leandro: «La economía española a fines de siglo», pp. 206-208. COMín, Francisco: «La liquidación del desastre», pp. 210-211. FernÁNDEZ CLEMENTE, Eloy: «Regeneracionismo: los límites de la utopía», pp. 213-217. FORCADELL, Carlos: «Las Cámaras de Comercio», pp. 218-219. Ricardo Robledo, "Agrarismo a fines del XIX», pp. 223-225.

42 DE BLAS, Andrés: «Refundación del nacionalismo español», pp. 229-234. VARELA, Javier: «Nacionalismo económico», pp. 235-237. MORALES, Antonio y EsteBAN, Mariano: «Literatura del Desastre», pp. 238-239. CULlA, Joan: «Escolta, Espanya», pp. 245-249. DuARTE, Ángel: «La tradición democrática popular y el catalanismo», pp. 250-252. DE RIQUER, Borja: «El 'seny' ordenador de Cataluña», pp. 256-258. JUARISTI, Jon: «País Vasco: la fractura social», pp. 261-266. DE LA GRANJA, José Luis: «La invención de la nación vasca», pp. 273-275. CORCUERA, Javier: «Los primeros pasos del nacionalismo vasco", 267-269.

43 Calvo Serrater, Francisco: «Ciudad y paisaje», pp. 277-282. Del Moral, Carmen: «El 98 y el género lírico español», pp. 283-285. SÁNCHEZ, Agustín: «Una nueva arma: el cine», pp. 286287. CARlos MAINER, José: «Crisis de fin de siglo y literatura», pp. 293-298.

44 MesA, Roberto, ed.: Tiempo del 98, Sevilla, Fundación El Monte, 1998. 
En segundo lugar, el volumen Un siglo de España: Centenario, 1898-1998, coordinado por José Cayuela, fruto de un curso de doctorado impartido en varios años. El resultado ha sido una obra original porque se abordan temas muy diversos, algunos de los cuales apenas han sido abordados en otros trabajos. Así, entre los habituales capítulos dedicados a las relaciones coloniales, al entorno diplomático y a las repercusiones económicas, se encuentran perspectivas novedosas como la formación histórica y la quiebra del Imperio español en una visión a largo plazo - Ricardo Izquierdo y José G. Cayuela-; los lazos transoceánicos después del 98 a través de la emigración, la cuestión religiosa o la legislación -Aurea Matilde Fernández, Consuelo Naranjo, Angel Luis López Villaverde, M. ${ }^{a}$ Dolores González, Javier García y Gerardo Fernández-; una larga reflexión en torno al pensamiento regeneracionista, la idea de España y el impacto del 98 en el mundo de las letras - José Carlos Rueda, M. ${ }^{a}$ Dolores de la Calle, Mariano Esteban, Antonio Morales, Rafael Asín, Luis Enrique Otero, Atilano Domínguez, Julián Carvajal, Matías Barchino, Agustín MuñozAlonso, y Felipe Pedraza-; la creación de nuevas identidades en América después del 98 -Teresa Muñoz-; el legado intelectual y literario del 98 en el Caribe -Enrique Sosa, Jesús Benito, Juan Herrero y Ileana Sanz-; las transformaciones de los espacios geográficos —Félix Pillet, Nancy Pérez, María Skoczek, Sonia Montiel_-45.

Y finalmente, el libro editado por Pedro Tedde, Economía y colonias en la España del 98, en el cual Juan Velarde repasa las nuevas ideas económicas del fin de siglo; Pedro Tedde revisa el estado de la economía española en torno al 98; Jordi Maluquer recuerda el impacto de las guerras coloniales de fin de siglo sobre la economía española; Inés Roldán plantea la hacienda cubana en el período de entreguerras; Manuel Martín subraya la importancia del azúcar en las colonias españolas; Oscar Zanetti, Alejandro García y Astrid Cubano explican la economía de Cuba y Puerto Rico; Francisco Comín analiza la reforma en Hacienda de Fernández Villaverde; y José Luis García, Manuel González, Rafael Anes y Carles Sudriá plantean la economía financiera española después del $98^{46}$.

\section{- Revistas}

Un número importante de las revistas especializadas en historia han dedicado monográficos al 98. Entre las revistas del CSIC, Hispania, se centró en la dimensión internacional del conflicto, a través de varios trabajos sobre las relaciones diplomáticas - Luis Alvarez, Cristóbal Robles, Rosario de la Torre-; sobre la transformación de Estados Unidos de nación en imperio - $\mathbf{M}^{a}{ }^{a}$ Dolores

45 Gregorio Cayuela, José, coord.: Un siglo de españa: Centenario 1898-1998, Cuenca, Universidad de Castilla-La Mancha, 1998.

46 TEDDE, Pedro, ed.: Economía y colonias en la España del 98, Madrid, Síntesis, 1999.

Hispania, LXI/2, núm. 208 (2001) 707-736 
Elizalde_-; sobre el impacto del 98 en el fin de siglo sudamericano - Mónica Quijada -; y sobre las finanzas de la guerra —-Inés Roldán — ${ }^{47}$; por su parte Revista de Indias, también del CSIC, dedicó tres volúmenes a la realidad colonial en Cuba, Puerto Rico y Filipinas en 1898, en los que intervinieron especialistas en cada uno de esos mundos ultramarinos ${ }^{48}$.

Studia Histórica, de la Universidad de Salamanca, reunió una buena serie de trabajos en torno al tema Cuba y el 98, entre los que cabe destacar por el interés o la originalidad de su enfoque los artículos de Enric Ucelay-Da Cal relacionando la realidad cubana finisecular con el despertar de los nacionalismos en la España peninsular; la reflexión de José A. Piqueras sobre la sociedad civil, la política y el dominio colonial en Cuba de 1875 a 1898; las investigaciones de Angel Bahamonde y José G. Cayuela sobre la élite colonial hispano-cubana; y el estudio de Alejandro García sobre la evolución de la economía cubana en las primeras décadas del siglo $\mathrm{XX}^{49}$.

La Revista Española del Pacífico publicó un monográfico sobre Filipinas en 1898 con una serie de artículos interesantes - Luis Angel Sánchez, Michael Cullinane, Leoncio Cabrero, Walter LaFeber, Willem Wolters, entre otrosque aportaron aspectos poco conocidos de nuestra historia colonial ${ }^{50}$.

Los Cuadernos de Historia Contemporánea, de la Universidad Complutense, presentaron una serie de ensayos sobre el 98 abordados desde distintas perspectivas: en el plano político, un trabajo de Manuel Suárez Cortina sobre el republicanismo después de la crisis de fin de siglo, y un análisis de Martínez Sanz acerca de la reflexión que se produjo en el Ejército tras la derrota; en el campo de la cultura, sendos artículos de Juan Pablo Fusi diferenciando el particularismo cultural de Cataluña, País Vasco y Galicia; de Alicia Langa sobre maestros literarios del 98; Guadalupe Gómez-Ferrer sobre Pardo Bazán; y de Alfredo Baratas sobre la ciencia española ante la crisis del 98; y finalmete, en el terreno ultramarino, Sylvia Hilton trató de la aplicación de la «doctrina Monroe» por McKinley en 1898; y Consuelo Naranjo abordó los imaginarios nacionales en $\mathrm{Cuba}^{51}$.

La revista Hacienda Pública, editada por el Instituto de Estudios Fiscales, planteó una revisión de la figura de Fernández Villaverde en Hacienda. En ella se resaltaba, sobre todo, el riguroso programa de saneamiento aplicado a una Hacienda que en 1898 presentaba una difícil situación financiera, agravada por

47 Hispania, Revista Española de Historia, CSIC, Madrid, vol. LVII/2, «La quiebra colonial española de 1898. Contexto internacional y dimensión fińanciera», 196, (1997), 427-675.

48 Revista de Indias, "Puerto Rico 1898", coord. por AGRAIT, Luis y CuBANO, Astrid, 211, (1997), 625-799. Revista de Indias, "Cuba 1898», coord. por GARCÍA, Alejandro y NARANJO, Consuelo, 212, (1998), 7-293. Revista de Indias, «Filipinas, 1898», coord. por NARANJO, Consuelo, 213, (1998), 307-527.

49 Studia Histórica. Historia contemporánea, Universidad de Salamanca, 15, (1997), 3-264.

so Revista Española del Pacífico, 9, (1998), 5-311.

51 Cuadernos de Historia Contemporánea, 20, (1998), 103-239. 
las guerras coloniales. Ese programa se materializó en la consecución de una nivelación presupuestaria, conseguida a través de una reforma tributaria, una reducción del volumen de la deuda pública y un control de la oferta monetaria. En el número se discutían distintas facetas de la labor de Villaverde y se abordaba el espíritu detrás de sus reformas, señalando tanto sus logros como sus limitaciones. Hemos reseñado este volumen en el capítulo dedicado a revistas, pero realmente, dada la coherencia temática del número y la calidad y complementariedad de las aportaciones, se convierte en mucho más que la suma de unos artículos expuestos secuencialmente en una revista, y bien podría considerarse una monografía colectiva ${ }^{52}$.

\section{- Obras de autores individuales}

Finalmente, nos queda por reseñar el capítulo de libros de autores individuales. Es curioso constatar que es precisamente en este punto donde más escasa se ha mostrado la revisión del 98 , cien años después. Hemos visto que han sido numerosas e importantes las contribuciones de volúmenes colectivos. Sin embargo, los libros unipersonales han sido muchos menos en relación con lo que cabía esperar: al menos cinco o seis grandes reflexiones sobre el 98 realizadas por autores consagrados en la materia. En su mayor parte, esos grandes libros han faltado a la cita.

Afortunadamente, se han publicado una serie de obras interesantes. Entre ellas, una de las pocas reflexiones sobre la guerra en sí, tema casi totalmente ausente en la actual revisión: en La Guerra de Cuba (1895-1898). Historia política de una derrota colonial, Antonio Elorza y Elena Hernández Sandoica plantearon mucho más de lo que el título anunciaba. En él abordaron la situación de Cuba antes de la guerra y la insertaron en el sistema político de la Restauración; explicaron el desarrollo del conflicto, la intervención de los Estados Unidos y la actuación del Gobierno español. Finalmente, expusieron las reacciones de la opinión pública ante lo acaecido ${ }^{53}$.

52 Hacienda Pública Española, Monografías 1999, «Villaverde en Hacienda, cien años después», Instituto de Estudios Fiscales, 1999. Entre sus artículos cabe destacar los de SOLÉ, Gabriel: «La reforma de Raimundo Fernández Villaverde», pp. 21-31; ROLDÁN, Inés: «Los efectos de la guerra colonial sobre la hacienda española»; VALLEJO, Rafael: «La Hacienda española durante la Restauración, ¿quietismo fiscal?», pp. 47-72; SABATÉ, Marcela y SERRANO, José $\mathrm{M}^{\mathrm{a}}$ : «La política monetaria de Fernández Villaverde», pp. 93-104.; COMÍn, Francisco: «El arreglo de la deuda: la pieza clave de la política de nivelación de Villaverde», pp. 105-119; DEL REY, Fernando: «La protesta de los 'productores' contra las reformas fiscales de Raimundo Fernández Villaverde, 1898-1900», pp. 235253; y una revisión los distintos tipos de impuestos introducidos por Villaverde elaborada por diferentes autores.

53 Antonio Elorza y Elena Hernández Sandoica, La Guerra de Cuba (1895-1898). Historia política de una derrota colonial, Madrid, Alianza, 1998. En este tema también pueden citarse la obra de Antonio Marimón, La crisis de 1898, en la cual tras una breve introducción a las guerras de 1895-

Hispania, LXI/2, núm. 208 (2001) 707-736 
Otra de las obras individuales más completas del 98 es el trabajo de José Andrés-Gallego, Un 98 distinto. Restauración. Desastre. Regeneracionismo, en el cual hace una radiografía del sistema político de la Restauración, analizando cómo era el Estado en sus diferentes variantes; señalando sus problemas y sus logros; y describiendo el camino hacia el 98 y la posterior reacción regeneracionista ${ }^{54}$.

Desde una perspectiva sectorial, referida a los aspectos económicos de la guerra de 1898, Jordi Maluquer presentó un ameno y completo fresco en el que analizaba las razones económicas que empujaron a la contienda; los hombres necesarios para hacer la guerra y el impacto demográfico de las batallas; las formas que se emplearon para obtener recursos con que poder financiar las guerras; las deudas que generaron y los mecanismos para liquidarlas; el impacto del 98 sobre la inflación, los salarios, el mercado colonial y la industria; y el auge monetario e inversor del fin de siglo. Finalmente, dedicaba una interesante reflexión sobre los economistas españoles ante la crisis de $1898^{55}$.

Otros libros plantearon análisis de cómo era España en 1898. Entre ellos, el cuadro de la época trazado por Rafael Nuñez Florencio, en el cual desgrana la vida política, la sociedad, las costumbres y el impacto que sobre todo ello tuvo la guerra del 98. Javier Figuero y Carlos G. Santa Cecilia elaboraron una crónica periodística del año del desastre, compuesta a base de noticias tomadas de la prensa diaria del 98. En esa misma línea se inscribe también el trabajo de Eslava Galán y Rojano Ortega ${ }^{56}$.

En el campo literario, varios autores individuales han debatido en torno a la generación del $98^{57}$. Leonardo Tobar ha trascendido esa discusión para ilustranos sobre los escritores de la Restauración ${ }^{58}$. La Editorial Biblioteca Nueva, bajo

1898, aportaba una selección de textos sobre las mismas, Ariel, Barcelona, 1998. Gabriel Cardona y Juan Carlos Losada elaboraron una interesante biografía de uno de los hombres clave en la política colonial española de fin de siglo, con una decisiva influencia en el desarrollo de la guerra de 1898: Weyler, nuestro hombre en La Habana, Barcelona, Planeta, 1997.

54 ANDRÉs-Gallego, Jose: Un 98 distinto, Restauración, Desastre. Regeneracionismo, Madrid, Ediciones Encuentro, 1998.

55 MALUQUeR DE MOTES, Jordi: España en la crisis de 1898. De la gran depresión a la modernización económica del siglo XX, Barcelona, Península, 1999.

56 NúNEZ Florencio, Rafael: Tal como éramos. España bace un siglo, Madrid, Espasa-Calpe, 1998. Javier Figuero y Carlos G. Santa Cecilia, La España del Desastre, Barcelona, Plaza\& Janés, 1997. J. Eslava Galán y D. Rojano Ortega, La España del 98. El fin de una era, Madrid, Edaf, 1997.

57 Laín EnTralgo, Pedro: La generación del 98, Madrid, Espasa-Calpe, 1997. LuIS Bernal, José: ¿Invento o realidad? La generación española de 1898, Valencia, Pre-textos, 1996. Inmax Fox también toca el tema en su obra La invención de España. Nacionalismo liberal e identidad nacional, Madrid, Cátedra, 1997, aunque amplía la perspectiva porque estudia los hitos del nacionalismo liberal español y de la construcción de una identidad nacional a través de un análisis de diferentes escuelas de pensamiento liberal, entre las que cita a los historiadores liberales de mediados del XIX y a las generaciones del 98 y del 14, pasando por la Institución Libre de Enseñanza.

${ }_{58}$ TOBAR, Leonardo: El camino hacia el 98. Los escritores de la Restauración y la crisis del fin de siglo. Leonardo Tobar, Ed. Madrid, Fundación Duques de Soria y Visor, 1998. A su reflexión se unen 
la dirección de Juan Pablo Fusi, ha reeditado una colección de textos clásicos del 98 comentados por especialistas actuales. Entre ellos, Hacia otra España, de Ramiro de Maeztu, con una introducción de Javier Varela y La moral de la derrota, de Luis Morote, ànalizado por Juan Sisinio Pérez Garzón.

Finalmente, nos quedaría por hacer un balance de lo que se ha hecho sobre el 98 en otros países, una reflexión que consideramos necesaria y complementaria pero que dada la longitud que ha adquirido este trabajo dejamos para una futura ocasión. El artículo se complementa también con las conclusiones que se pueden extraer de este repensar el 98, cien años después, obtenidas a través de la lectura de las obras relacionadas en este trabajo; dichas conclusiones han aparecido recientemente en forma de «Balance del 98» en la revista Historia y Política ${ }^{59}$.

\footnotetext{
valiosos trabajos sobre Pérez-Galdós, Valera, Clarín, las corrientes literarias de la época, las relaciones entre literatos y prensa periódica, etc.

59 ElizAlde, M. ${ }^{a}$ Dolores: «Balance del 98. Un punto de inflexión en la modernización de España o la desdramatización de una derrota», Historia y Política, 3 (2000) 175-206.
}

Hispania, LXI/2, núm. 208 (2001) 707-736 